\title{
NHÂ̂N XÉT MộT SỐ TÁC DỤNG KHÔNG MONG MUỐN KHI ĐIỀU TRI NGộ ĐỐc CẤP METHANOL BẰNG ETHANOL ĐƯờNG UỐNG
}

\section{TÓM TẮT}

Mục tiêu: Nhận xét một số tác dụng không mong muốn khi điều trị ngộ đốc cấp methanol bằng ethanol đường uống. Đối tượng và phương pháp nghiên cứu: Nghiên cứu mô tả tiến cứu trên có 61 bệnh nhân được chẩn đoán ngộ độc cấp methanol điều trị tại Trung tâm chống độc (TTCĐ) Bênh viên Bach Mai từ tháng 10/2016 đến tháng 7/2018 có chỉ định điêuu trị bằng ethanol $20 \%$ theo phác đồ. Kết quả: Tuổi trung bình: 46,7 \pm 15 tuổi, nam giới chiếm 93,4\%. Ngộ độc đường uống là chủ yếu $(98,4 \%)$, có 1 bệnh nhânngộ độc đường hô hấp $(1,6 \%)$. Nồng độ methanol máu cao, trung vi $126 \mathrm{mg} / \mathrm{dL}$. Các tác dụng không mong muốn khi sử dung ethanol đường uống là tình trang ức chế thần kinh trung ương $(18,2 \%)$, kích thích thân kinh trung ương $(18,2 \%)$. Ngoài ra, trên hệ tiêu hóa, tình trạng buô̂n nôn $(31,8 \%)$, nôn $(10 \%)$, tăng transaminase $(14,6)$ là biểu hiện hay gặp. Chỉ có 1 bệnh nhân có biếu hiện viêm dạ dày $(1,6 \%)$, không có bểnh nhân nào bị xuất huyết tiêu hóa và viêm tụy cẩp. Không gặp bệnh nhân nào có biến chứng viêm phổi sặc và hạ đường huyết, rối loạn điện giải. Kết luận: Nghiên cứu cho thây các tác dụng không mong muốn chính khi sử dụng Ethanol làm thuốc giải độc đặc hiệu cho bệnh nhẩn ngộ độc cấp methanol.

Tư khoá: methanol, ethanol đường uống, tác dụng không mong muốn.

\section{SUMMARY \\ ADVERSE EFFECTS OF ORAL ETHANOL THERAPY IN THE TREATMENT OF ACUTE METHANOL POISONINGS}

Objective: to assess the adverse effects of oral ethanol regimen in the treatment of the patients with acute methanol intoxication. Subjects and methods: The adverse effects were evaluated in 61 patients with acute methanol poisoning who were indicated ethanol $20 \%$ orally according to the protocol at Poison Control Center (PCC) of Bach Mai Hospital from October 2016 to July 2018. Results: Average age was $46.7 \pm 15(16-71)$ years old, male accounted for $93.4 \%$. Average age: $46.7 \pm 15$ years, male $93.4 \%$. The poisonings mainly were orally (98.4\%), however, there was one patient through respiratory tract $(1.6 \%)$. The median of blood methanol concentration was $126 \mathrm{mg} / \mathrm{dL}$. The side effects when using oral ethanol were central nervous system depression $(18.2 \%)$, central nervous stimulation $(18.2 \%)$. In addition, on the digestive system, nausea

*Trung Tâm Chống Độc - Bệnh viện Bạch Mai Chịu trách nhiệm chính: Đặng Thị Xuân Email: xuandangthi17@gmail.com Ngày nhận bài: 21.12.2020

Ngày phản biên khoa họ: 25.01.2021

Ngày duyệt bài: 10.2.2021
$(31.8 \%)$, vomiting (10\%), and increased transaminases (14.6) were common manifestations. Only one patient exhibited gastritis (1.6\%), no patient had gastrointestinal bleeding and acute pancreatitis. No patient had complications with aspiration pneumonia hypoglycemia, or electrolyte disturbances. Conclusions: Research shows the main undesirable effects when using Ethanol as a specific antidote for patients with acute methanol poisoning.

Keywords: methanol poisoning, oral ethanol, adverse effects

\section{I. ĐĂT VẤN ĐỀ}

Methanol hay còn gọi là methyl alcohol hay alcol methylic có công thức hóa học là $\mathrm{CH}_{4} \mathrm{O}$ hay $\mathrm{CH}_{3} \mathrm{OH}$ được người Hy Lạp cổ tình cờ phát hiện khi thủy phân gỗ. Methanol rất độc, khi ngộ độc tỷ lệ tử vong rất cao. Trong những năm gần đây, có nhiều vụ ngộ độc methanol được báo cáo tại nhiều quốc gia như Cộng Hòa Séc, Ecuador, Estonia, Kenya, Libya, Na Uy... trong đó có Việt Nam. Số lượng bệnh nhân ngộ độc methanol tại Trung tâm Chống độc (TTCĐ) bệnh viện Bạch Mai ngày càng tăng $[1,2]$.

Methanol được hấp thu nhanh chóng và hoàn toàn qua đường tiêu hóa nồng độ đỉnh đạt được sau 30 - 90 phút. Methanol khi vào trong cơ thể được enzym alcohol dehydrogenase (ADH) tại gan chuyển hóa thành acid formic, là chất rất độc gây toan chuyển hóa và tổn thương nhiều cơ quan trong bệnh cảnh ngộ độc methanol [3]. Ethanol và fomepizole là 2 loại thuốc đối kháng đặc hiệu trong điều trị giải độc đối với ngộ độc methanol. Ethanol có ái lực cao hơn methanol trênADH nên ức chế chuyển hóa methanol thành chất gây độc chính là acid formic. Do giá thành rẻ và có hiêu quả không kém formepizol nên ethanol được nhiều nước trên thế giới sử dụng điều trị trong ngộ độc methanol. Tuy nhiên sử dụng ethanol để đạt được tác dụng ức chế canh tranh cân đạt nồng độ ethanl máu ở mức cao, mức gây ngộ độc của ethanl, nên dễ có nhiều tác dụng không mong muốn. Vì vậy, chúng tôi tiến hành nghiên cứu nàynhằm mục tiêu nhận xét một số tác dụng không mong muốn khi điều trị ngộ đốc cấp methanol bằng ethanol đường uống tại TTCĐ BV Bạch Mai.

\section{II. ĐỐI TƯợNG VÀ PHƯƠNG PHÁP NGHIÊN CỨU 2.1 Đối tượng nghiên cứu - Tiêu chuẩn chọn bệnh nhân: Bệnh nhân}


được chẩn đoán ngộ độc cấp methanol điều trị tại Trung tâm Chống độc bệnh viện Bạch Mai từ tháng 10/2016 đến tháng $7 / 2018$ có chỉ định điều trị bằng ethanol

- Tiêu chuẩn loại trừ:

+ Ngộ độc phối hợp với chất khác ngoài ethanol.

+ Tiền sử bệnh có di chứng thần kinh trung ương

2.2 Phương pháp nghiên cứu

2.2.1. Thiết kế nghiên cứu: Nghiên cứu mô tả tiến cứu

2.2.2. Tiến hành nghiên cứu: thu thập số liệu theo mẫu bệnh án nghiên cứu:

- Lâm sàng

+ Thông tin bệnh nhân: tuổi, giới tính, nghề nghiệp, tiền sử bệnh tật

+ Khai thác bệnh sử: triệu chứng lâm sàng, thời điểm uống, thời gian uống tới khi xuất hiện triệu chứng đầu tiên, hoàn cảnh xảy ra ngộ độc.

\section{- Cận lâm sàng}

+ Cổng thức máu, sinh hóa máu

+ Khí máu động mạch: $\mathrm{pH}, \mathrm{HCO}_{3}, \mathrm{BE}, \mathrm{PO}_{2}, \mathrm{PCO}_{2}$

+ Xét nghiệm ethanol máu, methanol máu khi vào viện và khi kết thúc lọc máu. Ngoài ra để theo dõi điều trị, ethanol máu được đo sau khi bắt đầu dùng 1 giờ và khi kết thúc lọc máu.

+ Xét nghiệm áp lực thẩm thấu (ALTT) máu vào viện và sau lọc máu, khoảng trống áp lực thẩm thấu (KTALTT), khoảng trống anion

2.3. Xử lý số liệu. Số liệu được xử lý theo phương pháp thống kê y học, sử dụng phần mềm SPSS 16.0. So sánh giá trị 2 trung bình bằng Student test (Mann-Witney U test nếu phân bố không chuẩn), so sánh nhiều giá trị trung bình bằng bằng ANOVA test, so sánh tỷ lệ \% bằng test $X 2$ hoặc Fisher Exact test, mức ý nghĩa thống kê $95 \%$.

\section{KẾT QUẢ NGHIÊN CỨU}

3.1. Đặc điểm chung của các bệnh nhânnghiển cứu. Nghiên cứu 61 bệnh nhân ngộ độc methanol điều trị bằng ethanol đường uống, chúng tôi thấy:

Đặc điểm về tuổi

3.2. Một số tác dụng phụ khi sử dụng ethanol

3.2.1. Tác dụng không mong muốn trên thần kinh trung ương $(n=22)$

Bảng 3.2.1: Tác dưng không mong muốn trên thần kinh trung ương

\begin{tabular}{|c|c|c|c|c|c|c|c|}
\hline \multirow{2}{*}{ Tác dụng } & \multicolumn{2}{|c|}{ Chung $(\mathbf{n = 2 2})$} & \multicolumn{2}{|c|}{ Nghiện rượu (n=8) } & \multicolumn{2}{c|}{ Không nghiện rượu(n=14) } & \multirow{2}{*}{$\mathbf{~}$} \\
\cline { 2 - 7 } & $\mathbf{n}$ & $\mathbf{\%}$ & $\mathbf{n}$ & $\mathbf{\%}$ & $\mathbf{n}$ & \\
\hline Kích thích & 4 & 18,2 & 1 & 12,5 & 3 & 21,4 & \\
\hline Ức chế & 4 & 18,2 & 2 & 25 & 2 & 14,3 & \multirow{2}{*}{0,37} \\
\hline Bình thường & 14 & 63,6 & 5 & 62,5 & 9 & 64,3 & \\
\hline Co giật & 0 & 0 & 0 & 0 & 0 & 0 & \\
\hline
\end{tabular}

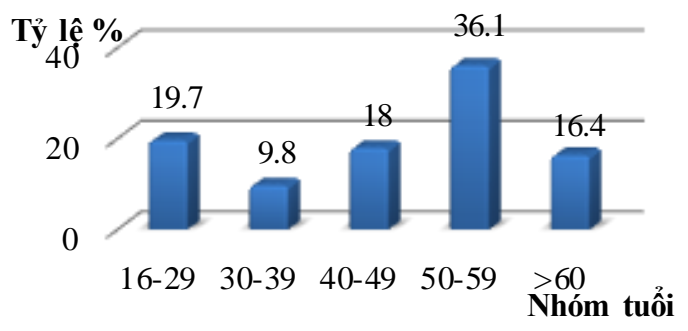

Biểu đồ 1: Phân bố BN theo nhóm tuổi

Nhận xét: - Tuổi trung bình: 46,7 \pm 15 tuổi, nhỏ nhất là 16 tuổi, cao nhất là 71 tuổi.

- Nhóm tuổi 40 - 59 chiếm thành phần chủ yếu $(54,1 \%)$.

- Đúng thứ 2 là nhóm tuổi từ 16 - 29 tuổi, chiếm 19,7\%.

Đặc điểm về giới tính

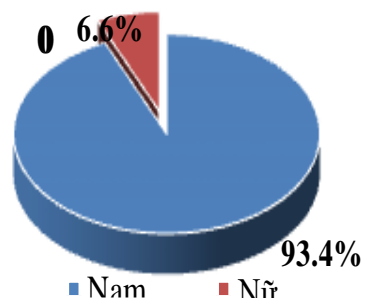

Biểu đồ 2: Phân bố BN theo giới tính

Nhận xét: Trong quần thể nghiên cứu, giới nam chiếm thành phần chủ yếu $57 / 61 \mathrm{BN}$ $(93,4 \%)$, nữ có $4 / 61 \mathrm{BN}(6,6 \%)$

Đường vào gây ngộ độc

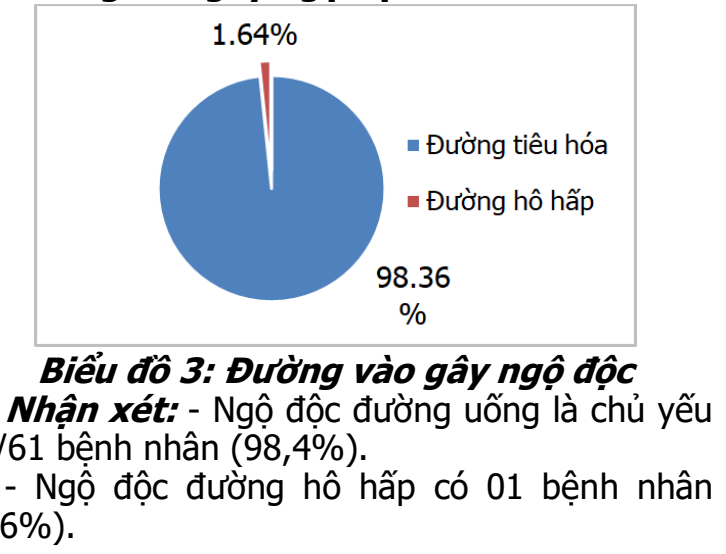

Biểu đồ 3: Đường vào gây ngộ độc

Nhân xét: - Ngộ độc đường uống là chủ yếu 60/61 bệnh nhân $(98,4 \%)$.

- Ngộ độc đường hô hấp có 01 bệnh nhân $(1,6 \%)$. 
Nhận xét: - Có 22 BN có ý thức tỉnh khi nhập viện và không dùng an thần được theo dõi tác dụng trên thần kinh trung ương, $08 \mathrm{BN}$ nghiện rượu, 14 BN không nghiện rượu.

- Biểu hiện kích thích thần kinh trung ương của 2 nhóm nghiện rượu và không nghiện rượu lần lượt là $12,5 \%$ và $21,4 \%$, biểu hiện ức chế thần kinh trung ương của 2 nhóm nghiện rượu và không nghiện rượu lần lượt là $25 \%$ và $14,3 \%$ khác biệt không có ý nghĩa thống kê với $p>0,05$.

- Chúng tôi không gặp biểu hiện co giật ở nhóm BN nghiên cứu khi dùng ethanol.

3.2.2. Tác dụng không mong muốn trên hệ tiêu hóa

3.2.1. Biểu hiện buồn nôn, nôn khi dùng ethanol đường uống

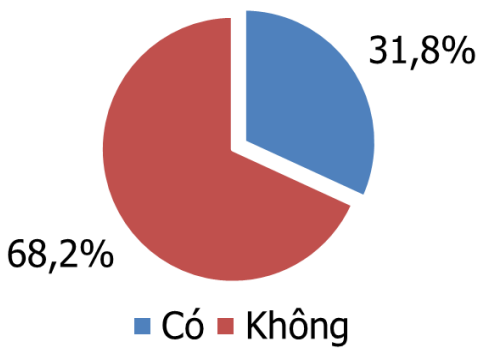

Biểu đồ 4: Biểu hiện buồn nôn khi dùng ethanol đường uống

Nhân xét: Có $22 \mathrm{BN}$ tỉnh khi nhập viện và được theo dõi biểu hiện buồn nôn, chỉ có $7 \mathrm{BN}$ có biểu hiện buồn nôn chiếm 31,8\%

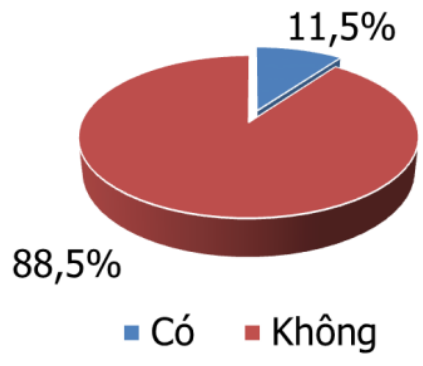

Biểu đồ 5: Biểu hiện nôn khi dùng ethanol đường uống

Nhân xét: Có 7/61 BN có biểu hiện nôn khi được dùng ethanol đường uống chiếm $10 \%$.

3.2.2. Mốt số biên chứng trên hề tiêu hóa khi dùng ethanol đường uống

Nhận xét: - Có 06/41 BN được theo dõi có biểu hiện tăng enzym transaminase chiếm $14,6 \%$

- Có 01/41 BN được theo dõi có biểu hiện viêm dạ dày chiếm $1,6 \%$

- Không có BN bị xuất huyết tiêu hóa và viêm tụy cấp

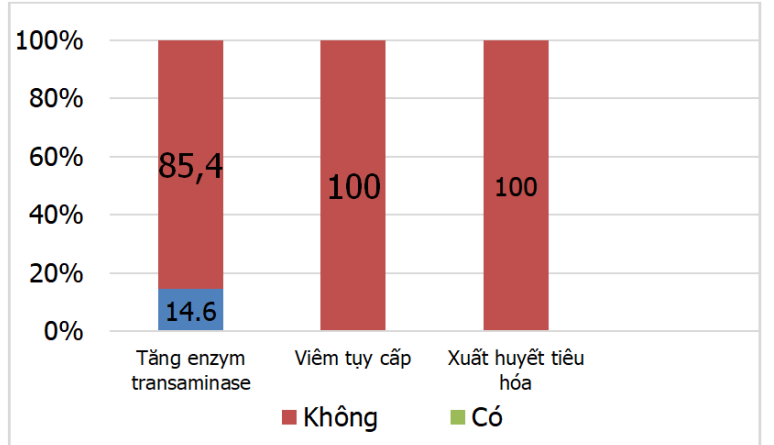

Biểu đồ 6: Môt số biến chứng trên hê tiêu hóa khi dùng ethanol đường uống

IV. BÀN LUẬN

4.1 Đặc điểm chung của các bệnh nhân nghiên cứu

Đặc điểm về tuổi. Tuổi bệnh nhân ngộ độc trong nghiên cứu của chúng tôi chủ yếu là trung niên $(36,1 \%)$, kết quả tương tự nghiên cứu của Phạm Như Quỳnh năm 2017 [2]. Tuổi trung bình bệnh nhân của chúng tôi cao hơn trong nghiên cứu của Gholamzera với $51,1 \%$ BN từ $20-29$ tuổi, chỉ có $23,5 \%$ BN trên 40 tuổi [4]. Nguyên nhân có thể do sự khác biết về văn hóa và lứa tuổi bắt đầu uống rượu.

Đặc điểm về giới tính. Ở Việt Nam có thể do nam giới có thói quen uống rượu nhiều hơn nữ giới và tỉ lệ nam giới nghiện rượu cao hơn ở nữ. Do vậy nguy cơ ngộ độc methanol lẫn trong rượu uống ở nam giới là chủ yếu (93.4\%).

Đường vào gây ngộ độc. Trong nghiên cứu của chúng tôi, ngộ độc đường uống là chủ yếu 60/61 BN (98,36\%). Có 01 BN ngộ độc đường hô hấp do tiếp xúc với hơi methanol trong thời gian dài. Nghiên cứu của chúng tôi khác với nghiên cứu của Nguyễn Đàm Chính, Phạm Như Quỳnh, Barceloux ngộ độc đường uống là $100 \%$ [1],[2],[5]. Trên thực tế, ngộ độc methanol đường hô hấp là rất hiếm gặp.

\subsection{Một số tác dụng không mong muốn}

Tác dụng trên thần kinh trung ương. Một trong những tác dụng không mong muốn thường gặp của ethanol là tác dụng ức chế thần kinh trung ương. Tuy nhiên, trước khi bị ức chế, chúng ta có thể gặp tình trạng kích thích thần kinh trung ương do thoát ức chế của vỏ não vùng thấp.

Các bệnh nhân trong nghiên cứu của chúng tôi hầu hết vào viện trong tình trạng rối loạn ý thức, chỉ có 22 BN có ý thức tỉnh khi nhập viện, điểm Glasgow trên 12 điểm và không dùng an thần được theo dõi tác dụng trên thần kinh trung ương, với 8 bệnh nhân nghiện rượu, 14 bệnh 
nhân không nghiện rượu. Có 4 (18,2\%) bệnh nhân có tình trạng kích thích thần kinh trung ương với biểu hiện nói nhiều, hưng cảm, có BN biểu hiện la hét không hợp tác với nhân viên y tế, thậm chí cũng có BN có trạng thái hung hãn. Tình trạng ức chết thần kinh trung ương với 4 $\mathrm{BN}$ chủ yếu là giảm đáp ứng với kích thích từ bên ngoài như lời nói, tiếng động, đôi khi có trạng thái ngủ ngà, không có $B N$ nào hôn mê sâu cần phải đặt nội khí quản. Chúng tôi không gặp $\mathrm{BN}$ nào có biểu hiện co giật, trong nghiên cứu của Beatty là $0,6 \%$, còn tác giả Zakhazov cũng không gặp BN có biến chứng co giật [6], [7].

Tác dụng không mong muốn trên tiêu hóa. Khi dùng ethanol, đặc biệt ethanol đường uống, tác dụng không mong muốn cũng thường hay gặp là các biểu hiện ở hệ tiêu hóa, như buồn nôn, nôn, viêm dạ dày, tăng enzym transaminase, viêm tụy cấp...

Chúng tôi có $22 \mathrm{BN}$ tỉnh khi nhập viện và được theo dõi biểu hiện buồn nôn, trong quá trình sử dụng ethanol đường uống có $07 \mathrm{BN}$ có biểu hiện buồn nôn chiếm $31,8 \%$. Có 06 BN trong tổng số $61 \mathrm{BN}$ có biểu hiện nôn chiếm $10 \%$, tất cả các $B N$ này đều thuộc nhóm đối tượng không nghiện rượu. Chính biểu hiện nôn đã làm cho việc sử dụng ethanol đường uống gặp khó khăn, làm nồng độ ethanol máu không đạt được nồng độ điều trị.

Có $41 \mathrm{BN}$ thời gian điều trị trên 2 ngày và được theo dõi enzym GOT, GPT, chúng tôi thây có 06 BN khi vào viện enzym GOT, GPT ở mức bình thường hoặc gần mức bình thường, nhưng những ngày sau đó thì enzym GOT, GPT tăng cao. Biểu hiện tăng enzym GOT, GPT tăng cao nhất ở ngày thứ 2 với GOT cao nhất là $278 \mathrm{UI} / \mathrm{l}$, GPT cao nhất là 234 UI/I và giảm dần từ ngày thứ 3, enzym GOT tăng nhiêu hơn enzym GPT, điều này cũng phù hợp với bệnh cảnh viêm gan do rượu.

Chúng tôi không gặp $\mathrm{BN}$ bị xuất huyết tiêu hóa và viêm tụy cấp. Nghiên cứu của chúng tôi tương tự, Wedge không gặp viêm tụy cấp [6]

Một số tác dụng không mong muốn khác. Trong nghiên cứu của chúng tôi tất cả $B N$ đều được nhịn ăn trong thời gian dùng ethanol, do đó chúng tôi chủ động cho nuôi dưỡng $B N$ bằng đường tĩnh mạch, trong đó có nuôi dưỡng bằng dung dịch glucose và theo dõi đường máu 3h/lân, chúng tôi không gặp BN nào có biểu hiện hạ đường huyết.

Về biến chứng viêm phổi sặc, chúng tôi cũng không gặp $\mathrm{BN}$ nào có biến chứng viêm phổi sặc sau liệu pháp ethanol đường uống. Chúng tôi không gặp biến chứng viêm phổi sặc, trong điều trị chúng tôi chủ động dự phòng viêm phổi sặc ngay từ khi $\mathrm{BN}$ nhập viện. Tất cả các $\mathrm{BN}$ của chúng tôi đều được nằm đầu cao, đặt sonde dạ dày và hút sạch dịch dạ dày trước khi cho ethanol vào dạ dày, đồng thời cũng dùng các thuốc giảm tiết dịch dạ dày cho bệnh nhân. Ngoài ra, chúng tôi cũng không gặp bệnh nhân nào hạ natri máu.

\section{KẾT LUÂN}

Tuổi trung bình của bệnh nhân là 46,7 \pm 15 tuổi, nam giới chiếm 93,4\%. Ngộ độc đường uống là chủ yếu $(98,4 \%)$, có 1 bệnh nhân ngộ độc đường hô hấp $(1,6 \%)$. Nồng độ methanol máu cao, trung vị $126 \mathrm{mg} / \mathrm{dL}$

- Ethanol có thể sử dụng như một thuốc giải độc đặc hiệu với ngộ độc methanol.

- Một số tác dụng phụ khi sử dung ethanol đường uống là: Trển hệ thần kinh: tình trạng ức chế thần kinh trung ương (18,2\%), kích thích thần kinh trung ương $(18,2 \%)$. Trên hệ tiêu hóa: tình trạng buồn nôn $(31,8 \%)$, nôn $(10 \%)$, tăng transaminase $(14,6)$. Trong nghiên cứu không gặp tình trạng viêm tụy cấp và xuất huyết tiêu hóa cũng như biến chứng viêm phổi sặc, hạ đường huyết, rối loạn điện giải.

\section{TÀI LIÊU THAM KHẢO}

1. Nguyễn Đàm Chính, Vũ Xuân Nghĩa, Hà Trân Hưng (2016). Đặc điểm cận lâm sàng chính của bệnh nhân ngộ độ̣c cấp methanol. Tạp chí Y dược học quân sự, 41(4), 172-177.

2. Pham Nhứ Quỳnh, Lê Đình Tùng, Hà Trân Hưng (2017). Hiệu quả của thẩm tách máu kéo dài trong điều trị bệnh nhân ngộ độc cấp methanol. Tạp chí Sinh lý học Việt Nam, 21(3), 13-20.

3. JacobsenD, Martin K.M, (2014). Methanol and Formaldehyd poisoning.Critical Care Toxicology, 895-901

4. Winchester J.F, (2014). Methanol, Isopropyl Alcohol, Higher Alcohols, Ethylen Glycol, Cellosolves, Acetone and Oxalate.Clinical management of poisoning and drug overdose 3rd edition, 35, 491-505.

5. Barceloux D.G, et al. (2002). American Academy of Clinical Toxicology practice guidelines on the treatment of methanol poisoning. J Toxicol Clin Toxicol, 40(4), 415-46.

6. Wedge M.K, et al. (2012). The safety of ethanol infusions for the treatment of methanol or ethylene glycol intoxication: an observational study. Canadian Association of Emergency Physicians CJEM, 14(5), 283-289

7. Beatty L, et al. (2013). A Systematic Review of Ethanol and Fomepizole Use in Toxic Alcohol Ingestions. Emergency Medicine International, Article ID 63805 